\title{
EDITORIAL
}

\section{Neuroprogression and staging in psychiatry: historical considerations}

\author{
Flavio Kapczinski, ${ }^{1}$ Luis Guilherme Streb $^{2}$ \\ ${ }^{1}$ Editor-in-Chief, Revista Brasileira de Psiquiatria. Universidade Federal do Rio Grande do Sul, Porto Alegre, RS, Brazil, University of Texas \\ Health Science Center at Houston, Houston, TX, USA. ${ }^{2}$ Hospital Nossa Senhora da Conceição, Porto Alegre, RS, Brazil.
}

The term neuroprogression has been put forward to account for the pathological rewiring of the brain that takes place with the progression of severe mental disorders. In the first description of neuroprogression, Michael Berk ${ }^{1}$ focused on the progressive nature of some cases of bipolar disorder. The study of neuroprogression has expanded rapidly ever since. In fact, at the time of writing of this editorial, 52 papers on this topic had already been published in different areas such as schizophrenia, early intervention in affective disorders, geriatric bipolar disorder, aging, obesity, and nicotine dependence. We believe that the concept has proven to be useful in understanding the multidimensional changes described in the context of illness progression in psychiatry.

We can track the origins of the concept of neuroprogression back to the Zeitgeist of psychiatric systematics in the mid-19th century. At the time, the motto was "from (clinical) forms to (disease) transformations," as stated by Kahlbaum. $^{2}$ In this context, the Belgian psychiatrist Guislain (1797-1860) used the concept of "vesanic dementia" to account for progressive mental decay secondary to insanity. ${ }^{3}$ Guislain's vesanic dementia referred to acquired forms of progressive cognitive failure following acute affective episodes of mental illness and as a final state of disease. Experienced French psychiatrists used the concept of "vesanisation" to describe patients that presented cognitive decay and a more "organic-like" clinical presentation after multiple episodes (Lepine J-P, personal communication, 2013). The word vesania in psychiatry comes from the Latin term used as a generic designation for madness, and was applied by Heinroth in his influential classification of 1802 as "Seelenstörung" (mental disorder). When vesanisation was used as a synonym of a malignant progressive course, the underlying concept was related to Guislain's vesanic dementia. The clinical observation that patients may present initially with a profile of discrete episodes and move toward a more pervasive clinical presentation has evolved to the notion that psychiatric disorders could be conceived in terms of staging systems. ${ }^{4}$ Early stages would correspond to populations at extremely high risk for the development of psychopathology, whereas late-stage defects would be related to more severe presentations.

The idea that psychiatric disorders could progress in stages was an important topic of discussion in the mid1800s. At that time, stages (Stadien) were used by authors such as Griesinger, ${ }^{5}$ Neumann, ${ }^{6}$ and Kahlbaum ${ }^{2}$ to describe a variety of clinical pictures within the course of disease, as well as to describe states preceding or following mental disease. Accordingly, Griesinger wrote that "there results a method of viewing insanity which recognizes in the different forms, different stages of one morbid process; which may indeed be modified, interrupted, or transformed by the most varied pathological circumstances, but which, on the whole, pursues a constant progressive course, which may proceed even to complete destruction of the mental life" (p. 207).

Neumann, around 1859, believed that "no forms of mental disease exist, but stages of one and same disease process" (in Kahlbaum, p. 41). He described "Hyperästhesia psychica" as a prodromal state of mental disorders (Guislain's "Phrenalgie"), much alike current models of staging suggest.

Griesinger captured that by stating: "it generally happens, that with patients who fall into insanity, (...) the attacks, as time advances, become longer and more serious, the lucid intervals shorter, and with each new attack the prognosis becomes more unfavorable" (p. 451-2).

The study of the biological basis of neuroprogression has the potential to aid in the identification of relevant targets for treatment and improve prevention of disease progression in various contexts of mental health. ${ }^{7}$ Moreover, careful study of the pathophysiology of neuroprogression may pave the way for staging systems based on biological findings, as is the case with other staging systems in medicine; hopefully, psychiatry will follow the same path in due course. Considerable efforts in translational research are required to put in place credible molecular targets for interventions aiming to prevent illness progression and, ultimately, the "vesanisation of" psychiatric disorders. This may help shape 21st-century psychiatry into a science devoted to helping people with mental disorders recover and return to their normal working and family lives.

\section{Disclosure}

FK has received grants/research support from AstraZeneca, Eli Lilly, Janssen-Cilag, Servier, CNPq, Coordenação de Aperfeiçoamento de Pessoal de Nível Superior (CAPES), NARSAD, and Stanley Medical Research Institute; has been a member of the board of speakers for Astra-Zeneca, Eli Lilly, Janssen, and Servier; and has served as a consultant for Servier. LGS reports no conflicts of interest. 


\section{References}

1 Berk M. Neuroprogression: pathways to progressive brain changes in bipolar disorder. Int J Neuropsychopharmacol. 2009;12:441-5.

2 Kahlbaum K. Die Gruppierung der psychischen Krankheiten und die Einteilung der Seelenstorungen. Danzig: AW Kafemann; 1863.

3 Haustgen T, Akiskal H. French antecedents of "contemporary" concepts in the American Psychiatric Association's classification of bipolar (mood) disorders. J Affect Disord. 2006;96:149-63.
4 Scott J, Leboyer M, Hickie I, Berk M, Kapczinski F, Frank E, et al. Clinical staging in psychiatry: a cross-cutting model of diagnosis with heuristic and practical value. Br J Psychiatry. 2013;202:243-5.

5 Griesinger W. Mental pathology and therapeutics. London: The New Sydenham Society; 1867.

6 Neumann H. Lehrbuch der Psychiatrie. Erlangen: Enke; 1859.

7 Gama CS, Kunz M, Magalhaes PV, Kapczinski F. Staging and neuroprogression in bipolar disorder: a systematic review of the literature. Rev Bras Psiquiatr. 2013;35:70-4. 